\title{
DESIGN OF A RESIDENTIAL BUILDING IN CONFINED URBAN SPACES IN TERMS OF DAYLIGHTING OPTIMIZATION AND INSOLATION OF FLATS - A CASE STUDY
}

\author{
A. IRINGOVÁ \\ Department of Building Constructions and Urban Planning, Faculty of Civil Engineering, University of Žilina, \\ Univerzitná 1, 01026 Žilina, Slovakia \\ E-mail: agnes.iringova@fstav.uniza.sk
}

\begin{abstract}
Urban density and its impact on the availability of daylight and direct sunlight in a residential building. The light comfort in the living spaces and the insolation of flats, the requirements. Influence of outdoor light intensity on the intensity of daylighting in the living spaces. Dimensional, shape, and layout solution of a residential building in the area with extremely high external shading by surrounding development - a case study.
\end{abstract}

Keywords: external shading, legislative requirements, equivalent shadow angle, light comfort, optimization of the building's volume and shape considering daylight and direct sunlight availability

\section{Introduction}

Sufficient amount of daylight and insolation of flats is one of the primary hygienic conditions for designing the residential environment. The intensity and evenness of daylight in the living space affects both the visual and hygienic aspect as well as the space perception. Nowadays, there is a considerable pressure from investors to situate apartment buildings even in the areas extremely shaded by surrounding development. In such cases it is necessary to look for other ways of designing façades; unlike the standard boundary conditions with an acceptable amount of external shading. It is not possible to situate an apartment building in the zone where an amount of external shading is extremely high.

The aim of this paper is to provide an insight into the architectural design of a residential building in city urbanism with a high amount of external shading using the example taken from the work practice.

\section{Criteria for light comfort and insolation of flats according to Slovak legislation}

The optimal light comfort in flats creates a basic condition for the healthy environment. Its parameters are crucial for good vision and secure visual and light comfort necessary for work and rest. From a hygienic aspect, the amount of diffused light falling on the reference plane, its distribution in space, direction and composition of the luminous flux, brightness distribution in the field of vision, and impacts worsening the visual comfort, especially dazzling and silhouette effect have been assessed. Nowadays, daylighting is assessed primarily - from the hygienic point of view considering the intensity and quality on the reference plane, and secondarily - in terms of energy savings achieved from the reduced use of artificial lighting. The daylighting criteria compulsory for flat designing are specified in STN 73 0580-2 in accordance with the Regulation No. 259/2008 of the Ministry of Health of the Slovak Republic on the detail requirements for the indoor environment in buildings and the minimal requirements for lower-standard apartments and accommodation facilities as amended by Regulations No. 210/2016 Coll. and No. 124/2017 Coll. The daylighting requirements in the project practice are assessed considering the optimization of light comfort and insolation of the planned flats as well as the façade shaded by the construction of other buildings. In this case, an amount of shading in affected living or work spaces is assessed. The criterion for assessing the daylight-

\footnotetext{
This is an open-access article distributed under the terms of the Creative Commons Attribution-NonCommercial 4.0 International License (https://creativecommons.org/licenses/by-nc/4.0/), which permits unrestricted use, distribution, and reproduction in any medium for non-commercial purposes, provided the original author and source are credited, a link to the CC License is provided, and changes - if any - are indicated.
} 
ing in affected spaces is an equivalent shadow angle which provides information on the availability of sky light on the outside of a window. The time reduction of direct sunlight falling on a window is defined by the limit time at the minimal sun height above the horizon.

\subsection{Daylighting requirements for planned flats}

The daylight intensity in living spaces is determined by the daylight factor $(D F)$ which is detected on a horizontal reference plane $0.85 \mathrm{~m}$ above the floor. The recommended $D F$ value $D_{\min }$ according to STN $730580-2$ should be $0.5 \%$ in each point on the reference plane in the living room. In the case of illumination from above or combined one (above and side), $D_{\text {min }}$ should be $2.0 \%$ (if the proportion of illumination from above is higher than a half of the resultant illumination on the reference plane). In two checkpoints in the middle of the living room perpendicularly to the windows $1 \mathrm{~m}$ away from the walls, the $D F$ value should be at least $0.75 \%$ and the mean value of the checkpoint pair should be at least $0.9 \%$. The recommended $D F$ value in the worst checkpoint in the living room with multi-wall windows is $1.0 \%$. The evenness of illumination of the working place and its immediate surroundings must not be lower than 0.2 . The place for visual tasks is recommended to have the limited dazzling UGR - 19.

\subsection{Insolation requirements for planned flats}

According to STN 734301 Residential buildings, at least $1 / 3$ of living space in all newly planned flats it is required to have minimal insolation time 1.5 hours a day over the period from 1 March to 13 October, when the sun is higher than $5^{\circ}$. The flats with two or more living rooms should have 3 -hour insolation at least in one room.

The insolation time must be kept under the boundary conditions specified in STN 73 4301. In Slovakia, the unified geographic northern latitude of $49^{\circ}$ is used for assessing the insolation time in residential buildings. The insolation time is determined in true solar time. The orientation of a building and site-layout needs to be supported by reliable documents.

\subsection{Legislative requirements for outdoor illumination of existing shaded flats}

The allowable amount of external shading in contemporary urbanism is given in relevant legislation. Urban density considering the location and height-zoning is, in terms of diffused light availability on the shaded façade, defined in Regulation No. 259/2008. The assessment methodology and criteria are specified in STN 730580 Daylighting in Buildings 1, 2, Revision 2 in 2000. The equivalent or sector equivalent shadow angle is the assessment criterion for allowable amount of external shading. The value of equivalent shadow angle is influenced by the building's location and its commercial attractiveness as well as the real possibilities of the estates in terms of historical development of existing buildings. Commercial attractiveness of estates in urban planning is determined and authorized by the City Council. The sites are plotted into the city map and the boundaries of particular zones are determined. The limit value of the equivalent shadow angle may be $5^{\circ}$ higher if the sites are terraced. The maximal allowable value of the equivalent shadow angle goes for the shaded floor that is at the level of the lowest residential floor, it is typically the 1 st floor.

The value of allowable equivalent shadow angle is based on the real urban conditions. Its current allowable value in historic zones is the highest $-42^{\circ}$. The rate of superelevation to the distance of the opposite buildings 1:1 was applied in historic development, which affected the headrooms and heights of the windows on the lowest floors. The windows on higher floors in the historic buildings were differently high.

The allowable value of external shading in the second zone is up to $36^{\circ}$. It refers to the façades of buildings situated in the zones that are highly attractive. The owners often want such real estates to be more valuable, e.g. buildings in historic zones or busy streets attractive to investors where the shading is allowable only towards the street. The generally applicable allowable value of external shading for all other zones is max. $30^{\circ}$.

\subsection{Legislative requirements for the availability of direct sunlight in flats shaded by planned buildings}

In accordance with the Regulation No. 259/2008 and STN 734301 Residential buildings, the planned, i.e. shading buildings must be placed in the location in such a way that the insolation of the shaded flats can be at least 1.5 hours a day (1 March to 13 October) when the sun is higher than $5^{\circ}$.

\section{Daylighting intensity}

\subsection{Outdoor illumination}

Daylight is characterized by continuous dynamic changes. Its intensity depends directly on the optical properties of the atmosphere, amount of clouds, and sun's position - see the course of horizon illumination shown in Fig. 1. The sky illumination ranged from 0 to $90,000 \mathrm{~lx}$. It follows that the daylighting intensity is very variable. The actual illumination of the horizon in our climatic conditions depending on the season, sky condition, and day hours, ranges from 0 to $120,000 \mathrm{~lx}$. 


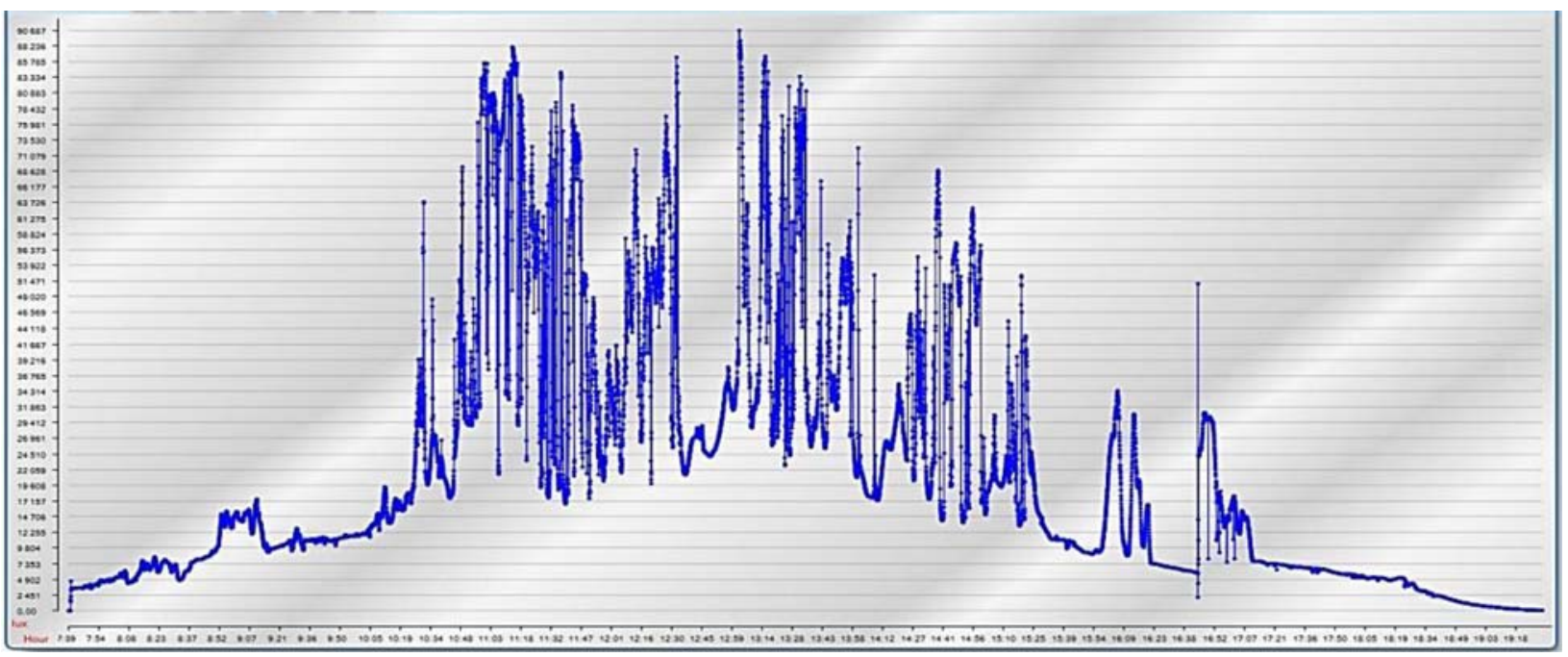

Fig. 1. The course of horizon illumination (lx) in the semi-cloudy sky, 07:50 - 19:00, 2 April, northern latitude of $49^{\circ}$

The International Commission on Illumination (CIE) standardised two extreme sky conditions - the cloudy sky with gradation of brightness (so-called CIE overcast sky) and the clear sky. The overcast winter sky (CIE 1:3) is a traditional model used for dimensioning room geometry and window size and verifying the sufficient daylighting on the reference plane in computational models. The level of brightness of such a sky does not depend on the azimuthal direction; it grows evenly from the horizon to the zenith. Therefore the window orientation is not so important when designing its size. The requirements for visual comfort must be kept under all light conditions. The solution uses the principle of minimum based on the following preconditions: if the room hygienic minima required are kept under this condition, they are supposed to be met for all other boundary conditions of illumination during a year. The real intensity of $D F$ in rooms during a year, depending on the orientation and availability of direct sunlight, is variable and higher than limits required. This is true even if light-transmitting barriers - greenery, blinds, solar shades, or sun screens - are situated in the light distribution path.

\subsection{Urban density and its influence on daylighting intensity}

The second aspect affecting the daylighting intensity in the assessed room is the urban density and the shading of windows by an obstacle standing in the path of light distribution. The elevation of an obstacle to the reference plane and its position (parallel or perpendicular to the assessed window) affects the intensity and evenness of diffusion light in the space as well as visual contact of the occupants with the sky. The exterior light fundamentally affects light comfort in planned flats and has a major impact on the window design and geometry, room depth, and façade configuration.

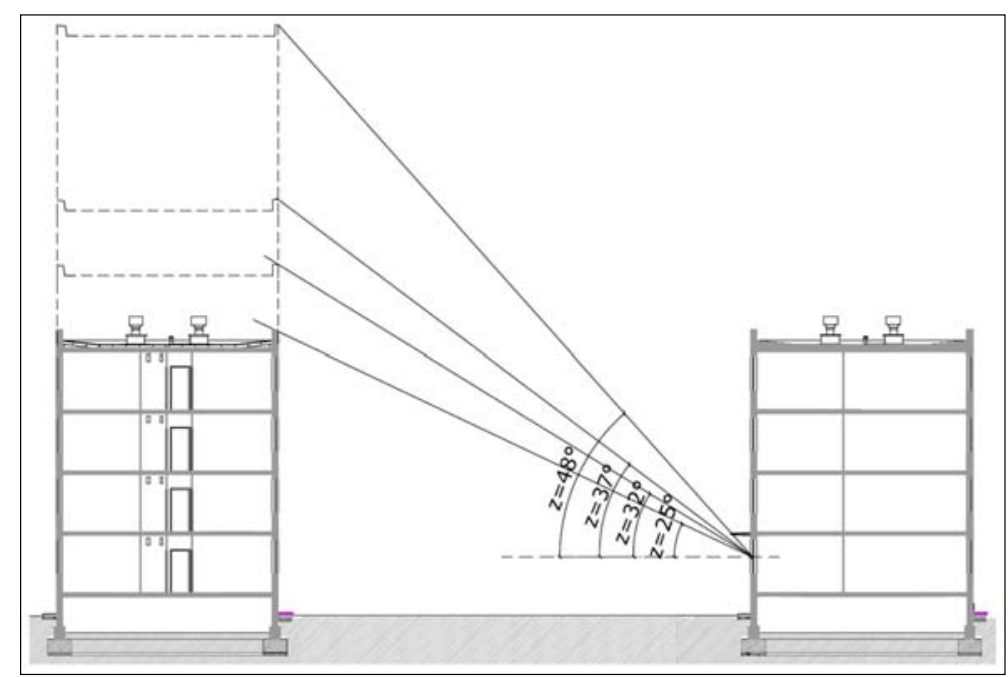

Fig. 2. Cross-section with an equivalent shadow angle 


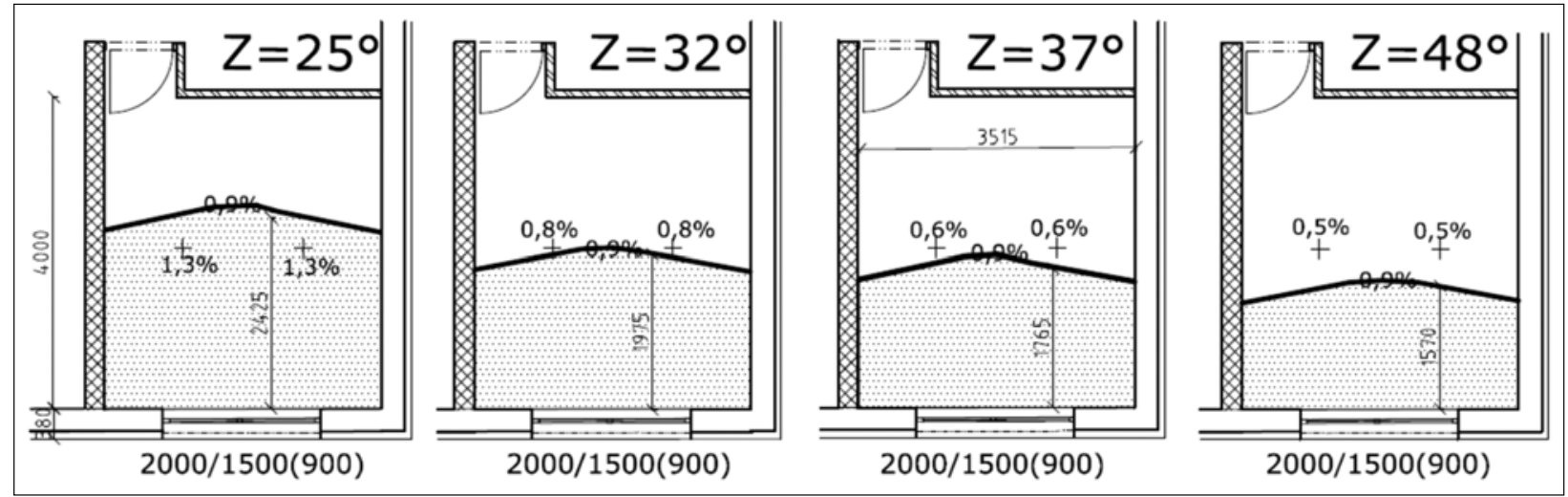

Fig. 3. $D F$ decrease affected by increasing shadow angle in a living room

The cross-section and layout of the model room in a residential building with the dependence on the external shading and $D F$ value is shown in Figs 2 and 3. Supposing the tall continuous shading of one side, the façade has no suspended elements and the room depth is optimized to $4 \mathrm{~m}$. The assessed room was 3.5 $\mathrm{m}$ wide and had a window $2 \mathrm{~m}$ wide and $1.5 \mathrm{~m}$ high with a $0.9 \mathrm{~m}$ sill. With respect to the room and window geometry, the required hygienic minimum in this room is met only if the external shading is $25^{\circ}-30^{\circ}$. If there is a higher amount of shading under the given boundary conditions, the limit value is not met. If the equivalent shadow angle is $32^{\circ}-37^{\circ}$, the solution is a larger window (max. $1.65 \mathrm{~m}$ high). The dependence of the window surface on the shadow angle in the assessed room in terms of the hygienic limit for the shadow angles up to $37^{\circ}$ is shown in Fig. 3. If there is a higher amount of shading, this solution cannot be applied. It is necessary to change the slope of glazing due to the boundary conditions in this site so that the sky can be visible through a part of a window.

\section{Optimization of the building's volume and shape in terms of light and direct sunlight availability - a case study}

The example below shows the design of an apartment building considering the daylight distribution on an extremely shaded site. The apartment building is situated in Záhorácka Street in the town of Malacky. Its southern facade is shaded by an opposite 9-storey apartment building with an elevation of the attic to the ground floor of the planned building about $27 \mathrm{~m}$. The distance between buildings is about $23 \mathrm{~m}$. The existing apartment building is an obstacle to the planned window wall with an equivalent shadow angle at ground level of about $48^{\circ}$. The calculation results for shading of vertical windows over $37^{\circ}$ indicate that the limit hygienic requirement of $D F$ cannot be met. As the sky is not visible from the checkpoint, only the reflected light falls on the limit point of the reference plane. The façade shape and window inclination had to be altered considering the amount of existing shading.

The task was to design a layout of an apartment building on the site extremely shaded by existing buildings. The building's location and window wall orientation was conditioned by an existing street line and surrounding buildings. The solution considering both the daylight distribution and insolation was to incline a window wall with roof windows so that the $D F$ sky component and the direct sunlight could reach the living spaces on each storey. The boundary conditions in the area are shown in Fig. 5. Figure 6 shows the resulting shape of the designed apartment building with a sloped window wall. The sloped façade contains roof windows $900 \mathrm{~mm}$ wide and $1600 \mathrm{~mm}$ high with

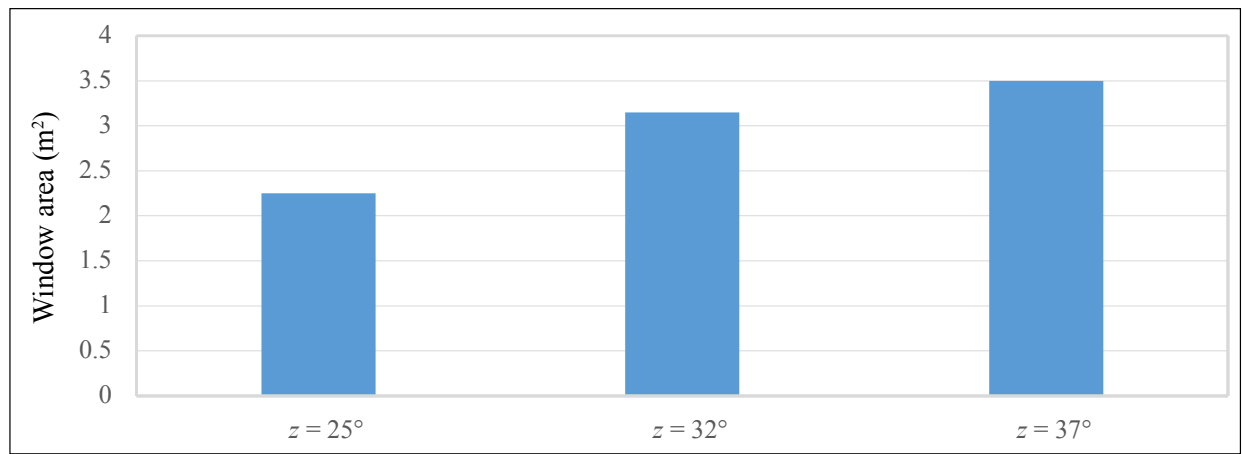

Fig. 4. Dependency of a window area on the equivalent shadow angle in a room $4 \mathrm{~m}$ deep at $D F=0.9 \%$ 


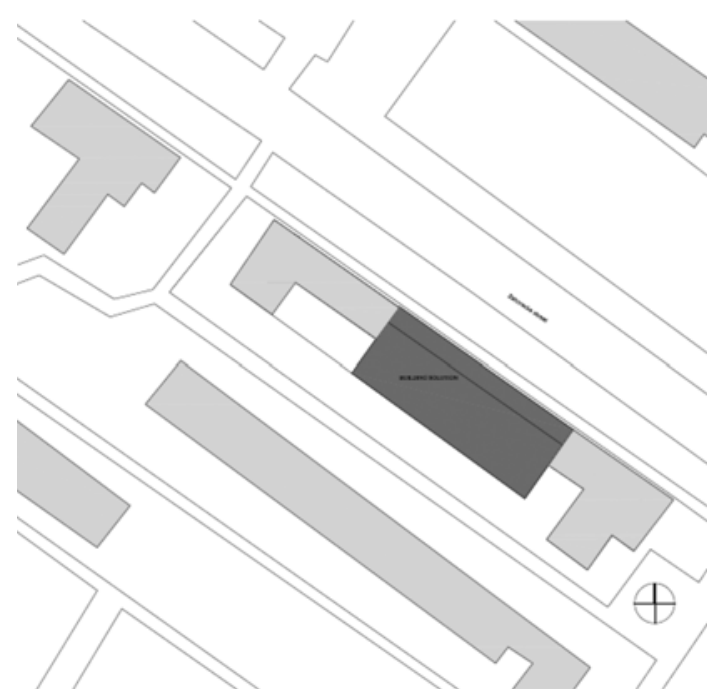

Fig. 5. Situation

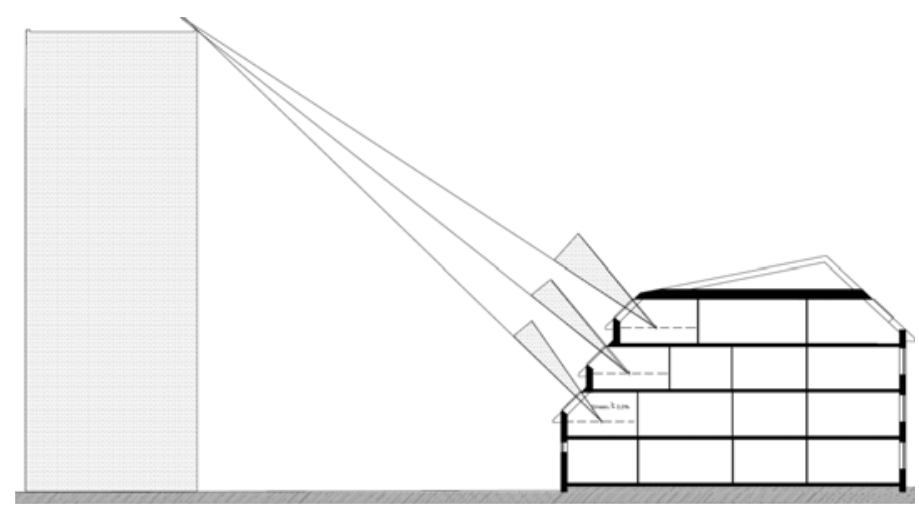

Fig. 6. Cross-section of a building
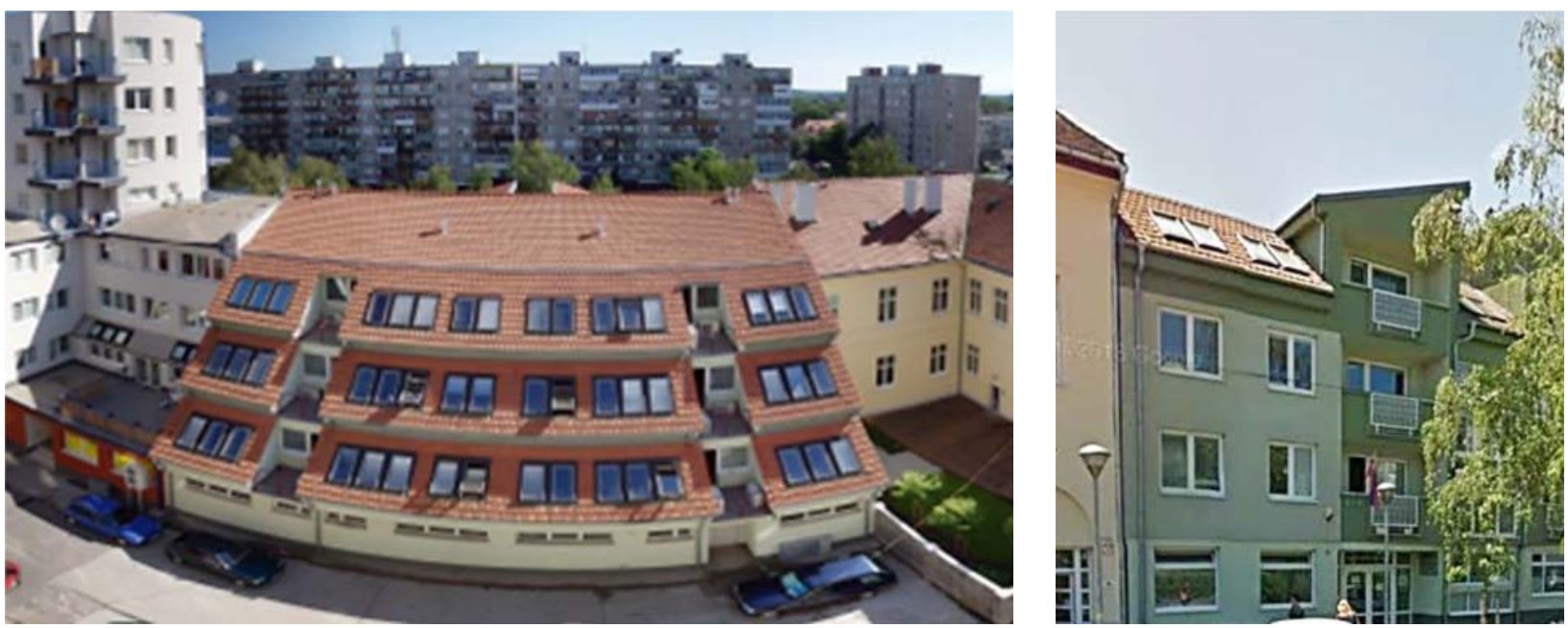

Fig. 7. View of the residential building: Left panel - yard side, right panel - street side (author's archive)

the glazing angle of $45^{\circ}$. The window sill is $1200 \mathrm{~mm}$. The windows are designed in such a way that the average $D F$ value in each room would be higher than $2 \%$. Each room has two or three windows, depending on its width. The view of the extremely shaded façade after the building had been completed is shown in Fig. 7, left. The street side of the façade contains vertical windows (see Fig. 7, right).

\section{Conclusions}

The trend of thickening and maximal utilization of the urban zones with less availability of standard non-collapsible building sites will continue. Architecture and the design of façade configuration and building volume will adapt to this trend and be a challenge for architects and designers to look for new forms and approaches so that the comfort in living spaces would be kept in all newly constructed buildings.

\section{Acknowledgements}

The paper presents the results of the project KEGA 032ŽU-4/2018 "Development of the educational support of the study program of the building construction".

\section{References}

[1] Regulation No. 259/2008 of the Ministry of Health of the Slovak Republic on the detail requirements for the indoor environment in buildings and the minimal requirements for lower-standard apartments and accommodation facilities as amended by Regulations No. 210/2016 Coll. and No. 124/2017 Coll.

[2] STN 730580 - 1 and 2 Daylighting in Buildings.

[3] Iringová A. Light-technical opinion of the apartment building, Peaceful Square, Malacky - architectural design by the studio Building Constructions, Nit'ová Street, Bratislava. 
[4] Katunský D., Dolníková E., Doroudiani S. (2017), Integrated lighting efficiency analysis in large industrial buildings to enhance indoor environmental quality. Buildings; $7(2), 1-20$.

[5] Hraška J. (2006), Dynamic simulations of daylighting in buildings. Heating, Ventilation, Installations, 4.
[6] Darula S., Kittler R. (2002), CIE general sky standard defining luminance distributions, Conference: Proc. Conf. eSim 2002. The Canadian conference on building energy simulation. 